\title{
HUBUNGAN ANTARA PENGGUNAAN PANTY LINER DENGAN KEJADIAN FLUOR ALBUS PADA REMAJA PUTRI DI SMK MUHAMMADIYAH 2 PEKANBARU
}

\author{
Isnaniar dan Raudatul Hasanah \\ Prodi D III Keperawatan Universitas Muhammadiyah Riau, Pekanbaru, Riau, Indonesia \\ E-mail: isnaniar@umri.ac.id, raudatulhasanah@studentumri.ac.id
}

\begin{abstract}
Abstrak
Tujuan penelitian ini adalah untuk mengetahui pengaruh penggunaan pantyliner terhadap kejadian keputihan pada siswi SMK Muhammadiyah 2 Pekanbaru. Desain penelitian ini adalah observasional analitik dengan pendekatan cross sectional. Sampel sebanyak 220 responden, dengan teknik random sampling. Data dianalisis menggunakan uji chi square dengan taraf signifikan $\alpha<0,05$. Penelitian ini menunjukkan bahwa H0 diterima dan Ha ditolak yang artinya tidak ada hubungan antara penggunaan panty liner dengan kejadian fluor albus pada siswi SMK Muhammadiyah 2 Pekanbaru. Kejadian keputihan pada siswi SMK Muhammadiyah 2 Pekanbaru disebabkan banyak faktor antara lain penggunaan panty liner yang tidak baik, pengetahuan yang kurang tentang fluor albus dan sumber informasi yang didapatkan tentang fluor albus. Hasil Penelitian yang telah dilaksanakan pada tanggal 27 Februari 2017 menunjukkan bahwa tidak ada hubungan antara penggunaan panty liner dengan kejadian fluor albus pada siswi SMK Muhammadiyah 2 Pekanbaru yaitu dari 108 Remaja yang menggunakan Panty liner didapatkan 106 (98,15\%) dengan nilai pvalue= 0,434. Kesimpulan penelitian ini bahwa dari 108 Remaja yang menggunakan Panty liner didapatkan 106 (98,15\%) Remaja mengalami Fluor Albus, hasil uji chi square menunjukkan tidak ada hubungan yang signifikan antara penggunaan panty liner dengan kejadian fluor albus di SMK Muhammadiyah 2 Pekanbaru, dengan nilai P-value 0,434. Saran bagi remaja putri yang menggunakan panty liner yaitu diharapkan pada remaja putri agar lebih berhatihati jika memilih dan menggunakan produk, Gunakan panty liner dengan lapisan berpori, mempunyai daya serap yang tinggi, dan mempunyai permukaan yang lembut, Jangan gunakan panty liner setiap hari, Gunakan panty liner hanya jika cairan yang keluar dari vagina terasa banyak, Jika menggunakan panty liner gantilah setiap 4-6 jam sekali, Setelah buang air kecil diharapkan agar mengganti panty liner yang digunakan, Gantilah panty liner jika keeadaan terasa lembab
\end{abstract}

Keyword : Penggunaan Pantyliner, Kejadian Keputihan 


\title{
RELATIONSHIP BETWEEN THE USE OF PANTY LINER WITH THE EVENT OF FLUOR ALBUS IN ADOLESCENT MANUAL IN SMK MUHAMMADIYAH 2 PEKANBARU
}

\author{
Diploma III Nursing Study Program of Muhammadiyah University of Riau \\ e-mail: isnaniar@umri.ac.id,raudatulhasanah@studentumri.ac.id
}

\begin{abstract}
The purpose of this study was to determine the effect of pantyliner use on the incidence of vaginal discharge at the Muhammadiyah 2 Vocational School 2 students in Pekanbaru. The design of this study was analytic observational with cross sectional approach. Samples were 220 respondents, with random sampling technique. Data were analyzed using chi square test with significant level $\alpha<0,05$. This study shows that $H 0$ is accepted and $\mathrm{Ha}$ is rejected which means that there is no relationship between the use of panty liner and the incidence of fluor albus in students of SMK Muhammadiyah 2 Pekanbaru. Leucorrhoea at Pekanbaru Muhammadiyah 2 Vocational School students was caused by many factors including poor use of panty liners, lack of knowledge about fluor albus and sources of information obtained about fluor albus. Results The research which was conducted on February 27, 2017 showed that there was no correlation between the use of panty liner and the incidence of fluor albus in the students of Muhammadiyah 2 Vocational High School in Pekanbaru, namely from 108 adolescents who used Panty liner obtained 106 (98.15\%) with pvalue $=0.434$. The conclusion of this study that out of 108 adolescents who used Panty liner obtained 106 (98.15\%) adolescents had Fluorine Albus, the results of the chi square test showed no significant relationship between the use of panty liner and the incidence of fluor albus in the Muhammadiyah 2 Vocational School in Pekanbaru. P-value 0.434. Suggestions for young women who use the panty liner is that it is expected that young women should be more careful when choosing and using products, Use panty liners with porous layers, have high absorption, and have a soft surface, do not use panty liners every day, Use a panty liner only if the fluid coming out of the vagina feels a lot. If you use a panty liner, replace it every 4-6 hours. After urinating, it is hoped that to replace the panty liner used, replace the panty liner if the condition feels moist.
\end{abstract}

Keyword : : $\quad$ use of pantyliner, vaginal discharge 


\section{PENDAHULUAN}

Pantyliner adalah pembalut wanita namun merupakan versi yang lebih tipis. Fungsi utamanya adalah menyerap cairan vagina yang keluar di luar hari-hari deras menstruasi. Panty liner ini merupakan pembalut yang ukurannya jauh lebih kecil dan lebih tipis dibandingkan pembalut biasa. (Runeman, 2004; Efendi, 2012). Keputihan merupakan salah satu permasalahan wanita tanpa mengenal usia. Keputihan dikalangan medis dikenal juga dengan istilah leukorrhea atau fluor albus, yaitu keluarnya cairan selain darah dari vagina, baik yang berbau ataupun tidak, disertai rasa gatal diarea setempat, dapat terjadi secara normal (fisiologis) maupun abnormal (patologis) (Badaryati,2012).

Menurut WHO jumlah wanita di dunia yang pernah mengalami keputihan adalah sebanyak $75 \%$, sedangkan wanita Eropa yang pernah mengalami keputihan sebesar 25\% (Zubier, F, 2002). Di Indonesia sekitar $90 \%$ wanita berpotensi mengalami keputihan. Ini dikarenakan Negara Indonesia merupakan daerah yang beriklim tropis, sehingga jamur dengan mudah berkembang dan mengakibatkan banyaknya kasus keputihan. Gejala keputihan juga dialami oleh remaja puteri yang berumur 15-24 tahun yaitu sekitar $31,8 \%$. Hal ini menunjukkan bahwa remaja lebih berisiko terjadinya keputihan. Pada tahun 2002 sebanyak 50\% wanita Indonesia pernah mengalami keputihan, kemudian pada tahun 2003 meningkat menjadi $60 \%$ dan pada tahun 2004 meningkat lagi menjadi hampir $70 \%$ wanita Indonesia pernah mengalami keputihan setidaknya sekali dalam hidupnya (Katharini, 2009).

Menurut Farage (2007) mengatakan bahwa jika menggunakan pantyliner pada saat keputihan akan meningkatkan tumbuhnya bakteri jahat didalam vagina. Penggunaan pantyliner dalam waktu 6 bulan dan jika frekuensi mengganti pantyliner tiap5 jam sekali, itu tidak membuat cairan yang keluar dari vagina berkurang, tetapi justru lebih banyak. Kao Indonesia telah menghadirkan kurang lebih 14 rangkaian produk pembalut dan 10 Panty Liner. Dari data penduduk Indonesia yang dilansir Kementerian Dalam Negeri pada media September 2011 silam, disebutkan bahwa dari 259 juta penduduk Indonesia (akhir Desember 2010), tak kurang 127 juta adalah penduduk berjenis kelamin perempuan. Dari jumlah 127 juta itu, sekitar separuhnya adalah pengguna aktif pembalut (Berita bisnis, 2012).

Menurut penelitian Persia Anissa (2013) dalam penelitian Hubungan pemakaian Panty Liner dengan kejadian Fluor Albus di Kota Padang didapatkan bahwa lebih dari separuh responden yang memakai panty liner mengalami fluor albus $(69,2 \%)$ dan $80 \%$ diantaranya mengganti panty liner $<2$ kali perhari. Uji statistik chi- square menunjukkan ada hubungan yang bermakna antara pemakaian panty liner dengan kejadian fluor albus $(\mathrm{p}<0,05)$ dan frekuensi penggantian panty liner perhari dengan kejadian fluor albus $(\mathrm{p}<0,05)$. Terdapat hubungan bermakna antara pemakaian panty liner dengan fluor albus pada siswi SMA di Kota Padang.

Berdasarkan survey awal yang telah dilakukan oleh peneliti pada tanggal 20 Agustus 2016 dengan menggunakan kuesioner di SMK Muhammadiyah 2 Pekanbaru pada 10 responden kelas $\mathrm{X}$ Jurusan Administrasi Perkantoran didapatkan data bahwa 8 orang (80\%) mengatakan pernah menggunakan panty 
Liner dan diantara 8 orang pengguna panty Liner, 6 orang $(60 \%)$ diantaranya pernah mengalami keputihan. Berdasarkan latar belakang masalah yang penulis uraikan diatas, maka penulis tertarik untuk mengangkat permasalahan ini dengan judul "Hubungan antara Penggunaan Pantyliner dengan Kejadian Fluor Albus Pada Remaja Putri di SMK Muhammadiyah 2 Pekanbaru".

\section{METODE PENELITIAN}

Jenis penelitian yang digunakan dalam penelitian ini menggunakan desain analitik korelasi yaitu penelitian untuk melihat hubungan antara penggunaan panty liner dengan kejadian fluor albus di SMK Muhammadiyah 2 pekanbaru dengan metode cross-sectional dan menggunakan pendekatan retrospektif yaitu pengumpulan data sekaligus pada satu waktu dan menggunakan data yang lalu (Notoatmodjo, 2010).

Pengambilan sampel pada penelitian menggunakan Probality Sampling (Simple Random Sampling), jumlah sampel sebanyak 220 siswi dan teknik pengambilan sampel dengan Stratified random sampling. Analisa data dilakukan secara universal dengan melihat hasil perhitungan frekuensi dan persentase dari penelitian. Analisa bivariat dilakukan untuk menganalisa hubungan variabel independen (penggunaan panty liner) dengan variabel dependen (kejadian fluor albus) yang dilakukan dengan pengujian statistic Chi-square dengan tingkat kemaknaan atau derajat kesalahan $(\alpha)$ 0,05 dan Confidence Interval $95 \%$ dengan menggunakan program komputer. Uji Chisquare digunakan untuk menguji perbedaan proporsi/ presentase antara beberapa kelompok data dan untuk mengetahui hubungan antara variabel kategorik tidak berpasangan (Dahlan, 2009).

\section{TINJAUAN TEORITIS}

\section{Panty liner}

Panty liner merupakan alas yang bentuknya seperti pembalut tetapi ukurannya jauh lebih kecil dan tipis dari pembalut biasa.Umumnya wanita menggunakan panty liner pada saat keputihan atau saat keluarnya lendir berlebih dari vagina (Lotfira, 2012). Panty liner memiliki 3 (tiga) lapisan, yaitu: lapisan permukaan, lapisan tengah, dan lapisan bawah. Lapisan permukaan berfungsi menyerap cairan agar masuk ke dalam lapisan tengah. Lapisan bawah berfungsi untuk menampung cairan agar tidak menembus ke pakaian dalam.

Adapun ciri-ciri panty liner yang baik, yaitu:

a. Memiliki permukaan dengan daya serap yang tinggi; Panty liner yang baik harus memiliki daya serap yang tinggi untuk menyerap cairan yang berlebih agar tetap kering dan tidak lembab.

b. Memiliki permukaan yang halus, lembut, serta aman bagi area kewanitaan; Panty liner yang digunakan akan berinteraksi secara langsung dengan kulit area kewanitaan sehingga saat disarankan memilih Panty liner yang lembut dan aman untuk menghindari infeksi dan iritasi.

c. Memiliki lapisan bawah yang berpori; Fungsi pori ini sendiri adalah untuk mengalirkan udara secara alami supaya area kewanitaan tidak terasa gerah. Meskipun demikian, pantyliner dengan lapisan bawah berpori yang baik akan 
tetap mampu menampung cairan agar tidak tembus ke pakaian dalam.

Sebagian besar perempuan malas untuk mengganti pakaian dalam, dan lebih banyak yang memilih menggunakan panty liner. Meski panty liner terkesan lebih praktis, tidak disarankan untuk menggunakannya dalam waktu yang lama. Penggunaan panty liner setiap hari ternyata justru dapat mengakibatkan infeksi, bakteri, jamur, serta jerawat atau bisul pada daerah kewanitaan. Panty liner juga dapat merusak iklim pada kulit karena suhu rata-rata kulit adalah $1,1^{\circ} \mathrm{C}$. Hal ini terjadi karena menggunakan panty liner membuat daerah kewanitaan semakin lembab, meskipun lapisan atas pantyliner memiliki daya serap untuk menjaga hygienitas daerah kewanitaan, akan tetapi bagian dasar pantyliner terbuat dari plastik, sehingga kulit tidak dapat bernafas lega karena kurangnya sirkulasi udara (Runeman, 2004; Efendi, 2012). Panty liner juga dapat meningkatkan bakteri vaginosis dan kandidiasis bertumbuh kembang dengan pesat sehingga dapat menyebabkan iritasi pada vagina (Paulo, 2011).

Kuman dari panty liner yang dipakai lagi setelah buang air akan berpindah ke organ genitalia, hal itu bisa terjadi karena organ genitalia perempuan dekat dengan lubang anus, berbeda dengan organ genitalia laki-laki yang jauh dari anus. "Karena itu, kalau kuman-kuman tersebut berada di bawah (tertinggal di pantyliner), takutnya mudah terbawa ke lubang genitalia sehingga menyebabkan terjadinya infeksi. Seperti yang kita ketahui, bakteri tumbuh lebih cepat pada area yang lembab dan bertemperatur tinggi. Ini berarti daerah kewanitaan, tepatnya didaerah labia majora dan klitoris, menjadi area yang tepat bagi tumbuh kembang bakteri. Jika sudah demikian maka risiko jerawat dan iritasi pada daerah genital pun semakin mengancam.

Wanita yang sehat senantiasa perlu waspada dalam menjaga kesehatan alat reproduksinya untuk berhati-hati memilih penggunaan panty liner sehat yang berkualitas dan bebas dari zat dioxin. Zat dioxin merupakan zat yang berbahaya yang efektivitasnya 2000 kali dari racun tikus, timbul akibat proses produksi karena penggunaan bahan kimia dan pemutih pantyl iner yang bahan dasarnya tidak berkualitas seperti kertas bekas, kardus bekas dan serbuk kayu. Zat dioxin sangat berbahaya karena bila pantyliner atau pembalut terkena darah haid maka zat dioxin menguap kedalam rahim dan dalam jangka panjang mempengaruhi metabolisme tubuh wanita serta memicu timbulnya kista, karker serviks, dan lainlain (Brooks, 2007).

Yayasan Lembaga Konsumen Indonesia (YLKI) merilis daftar dari sejumlah mereka pembalut dan Panty liner yang mengandung klorin yang bisa menyebabkan iritasi dan juga kanker. Dari 9 merek pembalut dan 7 merek pantyliner, semua mengandung klorin dengan rentang 5-55 ppm (S Adang, 2015).

Dari temuan ini YLKI merekomendasikan kepada konsumen agar lebih aman menggunakan pembalut kain. Bahwa zat klorin ini tidak ditemukan dalam pembalut kain. Selain itu, pembalut kain juga bisa dipakai ulang dan dicuci kembali. Tingkat keamanannya jangka panjang (Tulus Abadi, 2015).

Pemerintah sebenarnya telah memberi tahu bahwa klorin adalah zat yang berbahaya melalui Peraturan Menteri Kesehatan Republik Indonesia Nomor 472/MENKES/PER/V/1996 tentang 
Pengamanan Bahan Berbahaya Bagi

Kesehatan. Meskiupun begitu, tidak ada regulasi yang melarang adanya kandungan klorin dalam pembalut (Arum, 2015).

Menurut Ardiansjah dalam artikel DepKes dengan judul Pembalut yang beredar sesuai Syarat Kesehatan tahun 2015 mengatakan sulit dipungkiri, lantaran bekerja, banyak orang yang tidak sempat mengganti pakaian dalam, khususnya celana dalam. Meskipun tak mengganti celana dalam, untuk menjaga kelembapan daerah kewanitaannya, perempuan kadang memakai Panty Liner, atau pembalut tipis sekali pakai. Panty Liner terbuat dari bahan dasar plastik yang memiliki bantalan tipis untuk menyerapcairan. Panty liner sebenarnya bukan biang masalah, tetapi sebaiknya tidak dipakai setiap hari, apalagi menggunakannya dalam jangka waktu yang lama. Terlalu lama menggunakan Panty liner akan berbahaya bagi kesehatan organ kewanitaan. Panty liner yang tidak diganti dalam waktu beberapa jam akan lembab dan menjadi media tumbuhnya jamur atau bakteri (kuman), antara lain kuman Trichomonas vaginalis (Ardiansjah, 2015).

Keputihan adalah salah satu indikasi maslaah kesehatan pada organ kewanitaan. Keputihan biasanya ditandai dengan rasa gatal, bau tidak sedap, dan terkadang rasa nyeri. Selain itu, keputihan disertai infeksi akan berwarna kekuningan, kecoklatan, bahkan kemerahan jika sudah bercampur darah. Karena itu maka gantilah Panty liner setelah buang air. (Ardiansjah, 2015). Kuman dari panty liner yang dipakai lagi setelah buang air akan berpindah ke organ genitalia. Hal itu bisa terjadi karena organ genitalia perempuan dekat dengan lubang anus, berbeda dengan organ genitalia laki-laki yang jauh dari anus. Karena itu, kalau kuman-kuman tersebut berada di bawah (tertinggal di panty liner), ditakutkan mudah terbawa ke lubang genitalia sehingga menyebabkan terjadi infeksi.

Komponen dalam panty liner

Panty liner memiliki beberapa komponen tambahan di dalamnya, di antaranya adalah:

a. Mentol, kegunaan mentol pada pantyliner adalah untuk membantu membuat daerah kewanitaan menjadi terasa sejuk dan tidak panas, namun jika kadar mentol dalam pantyliner berlebihan justru membuat sensasi panas dan membuat kulit kering sehingga mudah teriritasi

b. Sirih, kegunaan sirih pada pantyliner adalah untuk membuat aroma vagina menjadi lebih wangi dan terasa segar (saptasari, 2012)

c. Aloevera, kegunaannya adalah untuk menghambat peradangan, serta menurunkan suhu dan menjaga kelembapan di vagina

d. Parfum, kegunaan parfum pada pantyliner adalah untuk membuaat aroma daerah kewanitaan menjadi lebih wangi, namun parfum yang digunakan dalam pantyliner banyak mengandung bahan kimia yang memacu terjadinya kaker serviks (Dr. Boyke, 2012).

Dampak pemakaian panty liner; Penggunaan pantyliner yang dipakai setiap hari ternyata justru dapat mengakibatkan infeksi bakteri, jamur, serta jerawat atau bisul pada daerah kewanitaan. Hal Ini terjadi karena pantyliner membuat daerah kewanitaan menjadi semakin lembab. Meskipun lapisan atas pantyliner memiliki daya serap untuk menjaga higienitas daerah kewanitaan, akan tetapi bagian dasar dari pantyliner ini terbuat dari plastik, sehingga kulit menjadi tidak dapat 
bernafas lega karena kurangnya sirkulasi udara.

Pemakaian panty liner merupakan salah satu faktor predisposisi timbulnya keputihan, menurut penelitian Farage, panty liner meningkatkan populasi Eubacterium species di vagina dan menurunkan jumlah dari Lactobacillus species di vagina sebagai flora normal. Pemakaian panty liner juga dapat mentransfer flora intestinal seperti Eschericia coli ke dalam vagina dan pemakaian panty liner non breathable dapat meningkatkan risiko Kandidiasis. Menggunakan panty liner pada saat keputihan dapat meningkatkan tumbuhnya bakteri jahat dalam vagina. Penggunaan panty liner dalam waktu 6 bulan dan frekuensi mengganti panty liner 5 jam sekali tidak membuat cairan yang keluar dari vagina berkurang, tetapi justru akan keluar lebih banyak.

Pemakaian pembalut (panty liner) dapat menyebabkan jumlah lendir yang dihasilkan lebih banyak. Maka seharusnya gunakanlah panty liner hanya ketika lendir keluar berlebihan. (Sari, 2012).

\section{Flour Albus}

Leukorea (white discharge, flour albus, keputihan) adalah nama gejala yang diberikan kepada cairan yang dikeluarkan dari alat-alat genital yang tidak berupa darah dan biasanya sering dijumpai pada penderita ginekologi. (Sarwono,2008). Flour albus merupakan keluarnya cairan selain darah dari liang vagina baik berbau maupun tidak berbau dan disertai rasa gatal di daerah kewanitaan (Kusmiran, 2011).

Klasifikasi dan Ciri-ciri Keputihan (fluor albus); Menurut Bahari (2012) keputihan (fluor albus) dibagi menjadi dua yaitu: keputihan fisiologis atau normal dan keputihan patologis atau abnormal. Keputihan fisiologis (normal) terjadi pada saat sebelum dan sesudah menstruasi, mendapatkan rangsangan seksual, mengalami stres berat, sedang hamil atau mengalami kelelahan. Pada keputihan fisiologis ini cairan yang keluar berwarna jernih atau kekunig-kuningan dan tidak berbau.

a. Keputihan fisiologis ialah keluarnya cairan dengan ciri-ciri:

1) Cairan berwarna jernih

2) Cairan tidak terlalu kental

3) Cairan berwarna putih atau kekuningan

4) Jika terkontaminasi oleh udara tidak disertai rasa nyeri dan tidak timbul rasa gatal yang berlebih

b. Keputihan patologis sering disebut dengan keputihan abnormal atau keputihan tidak normal yang dikategorikan sebagai penyakit. Dengan ciri-ciri yaitu:

1) Cairan yang keluar sangat kental

2) Cairan berwarna kekuningan

3) Cairan memiliki bau yang sangat menyengat

4) Jumlahnya yang berlebih menyebabkan rasa gatal, nyeri juga rasa sakit dan panas saat berkemih (Bahari, 2012).

Penyebab Keputihan (fluor albus); Menurut Manan (2011) penyebab keputihan patologis adalah sering menggunakan kloset di toilet umum yang kotor, terutama kloset duduk, membilas vagina dari arah yang salah atau dari anus ke arah depan, sering bertukar celana dalam atau handuk dengan orang lain, kurangnya menjaga kebersihan vagina, tidak segera mengganti pembalut saat terjadinya menstruasi, lingkungan sanitasi yang kotor, sering mandi berendam dengan air hangat dan panas (jamur yang menyebabkan leukorea lebih mungkin 
tumbuh di kondisi hangat) dan terdapat tiga infeksi umum yang berhubungan dengan keputihan yaitu vaginosis bakteri (BV), trikomoniasis dan kandidiasis (Sherrard, Donders \&White, 2011).

Penelitian yang dilakukan oleh Runeman et al tahun 2003 bahwa pemakaian panty liner akan meningkatkan suhu $1,5^{\circ} \mathrm{C}$, peningkatan kelembapan, dan peningkatan $\mathrm{pH}$ sebesar 0,6 di area vulva dan perineum. Keadaan ini akan meningkatkan kemungkinan terjadinya pertumbuhan kuman dan jamur patogen penyebab fluor albus.

Pencegahan Keputihan (fluor albus); Menurut Bahari (2012), terdapat beberapa hal dalam mencegah terjadinya keputihan yaitu, mengenakan pakaian berbahan sintesis yang tidak ketat, sehingga ruang yang ada memadai dan tidak terjadi peningkatan kelembaban maupun iritasi, tidak menggunakan bedak atau bubuk yang bertujuan membuat vagina harum atau kering. Bedak sangat kecil dan halus, hal ini mudah terselip dan tidak dapat dibersihkan, sehingga mengundang datangnya jamur pada vagina, tidak menggunakan kloset yang kotor karena memungkinkan adanya bakteri yang dapat mengotori organ kewanitaan, mengganti celana dalam secara rutin terutama jika berkeringat, mengurangi penggunaan pembersih pada vagina karena penggunaan yang terlalu sering akan membunuh mikroorganisme normal dalam vagina, Saat periode menstruasi sering mengganti pembalut minimal 3 kali sehari, panty liner digunakan saat dirasa perlu saja, jangan digunakan terlalu lama. Setia pada pasangan merupakan langkah awal untuk menghindari keputihan yang disebabkan oleh infeksi yang menular melalui hubungan seksual, mengurangi aktifitas fisik yang sangat melelahkan sehingga daya tahan tubuh melemah, hindari penggunaan tisu yang terlalu sering. Menurut Gul, Qamar, Jawaid, Bukhari \& Javed (2013) pH normal vaginal antara 3,8 dan 4,4 untuk mencegah terjadinya keputihan patologis sehingga dibutuhkan skrining untuk mencegah terjadinya IMS. Hal ini diperiksa dengan mengambil scraping spatula dari dinding vagina lateral dan berlaku untuk rekaman $\mathrm{pH}$ atau strip uji (Sparrow, 2001).

Jangan sering-sering menggunakan panty liner. Sebaiknya gunakan pantyliner sesuai dengan kebutuhan artinya hanya ketika mengalami keputihan yang sangat banyak, dan gunakanlah pantyliner yang tidak berparfum untuk mencegah iritasi, dan seringlah mengganti pantyliner saat keputihan. (Ika, 2011 dan Salika, 2010) Penanganan Keputihan (flour albus); Keputihan yang normal tidak perlu diobati dengan obat-obatan, tetapi tetap dirawat dengan menjaga kebersihan dan mencegah kelembaban yang berlebihan pada daerah vagina dengan menggunakan tisu dan sering mengganti pakaian dalam. Sedangkan Keputihan abnormal diobati dengan meminum obat dari dokter untuk membersihkan vagina dari agen penyebab keputihan (Kasdus, 2005). Keputihan yang disebabkan oleh trikomoniasis dapat diobati dengan metronidazole, sedangkan keputihan yang disebabkan kandidiasis dapat diobati dengan Mycostatin (Manuaba, 2009).

Dampak Keputihan (fluor albus); Dampak dari Keputihan adalah akan menimbulkan kuman yang dapat mendatangkan infeksi pada daerah yang dilalui mulai dari muara kandung kemih, bibir kemaluan sampai uterus dan saluran indung telur sehingga dapat menimbulkan penyakit radang panggul dan dapat 
menyebabkan infertilitas (Bahari, 2012). Akibat yang paling sering ditimbulkan karena keputihan adalah infeksi. Menurut Aulia (2012), macam-macam infeksi alat genital, antara lain:

a. Vulvitis sebagian besar dengan gejala keputihan dan tanda infeksi lokal. Penyebab secara umum jamur vaginitis.

b. Vaginitis adalah infeksi pada vagina yang disebabkan oleh berbagai bakteri parasite atau jamur. Infeksi ini sebagian besar terjadi karenakan hubungan seksual.Tipe vaginitis yang sering dijumpai ialah vaginitis karena jamur.

c. Serviksitis adalah infeksi dari servik uteri. Infeksi servik sering terjadi karena luka kecil bekas persalinan yang tidak dirawat dan infeksi karena hubungan seksual.Keluhan yang dirasakan saat adanya keputihan, mungkin terjadi kontak berdarah (saat berhubungan seksual terjadi perdarahan).

d. Penyakit radang panggul (Pelvic Inflammatory Discase) adalah infeksi alat genetalia bagian atas wanita, ini terjadi akibat hubungan seksual. Penyakit ini dapat bersifat akut ataupun menahun atau akhirnya menimbulkan berbagai penyulit yang berakhir dengan terjadinya perlekatan sehingga dapat menyebabkan kemandulan. Tandatandanya yaitu nyeri seperti menusuknusuk, mengeluarkan keputihan yang bercampur darah, suhu tubuh menjadi meningkat dan nadi yang meningkat, pernafasan bertambah, dan tekanan darah masih dalam batas normal

\section{HASIL DAN PEMBAHASAN}

Berdasarkan penelitian yang dilakukan pada tanggal 27 Februari 2017 di SMK Muhammadiyah 2 Pekanbaru, dapat diperoleh data-data mengenai
Hubungan antara penggunaan Panty Liner dengan kejadian Fluor Albus sebagai berikut:

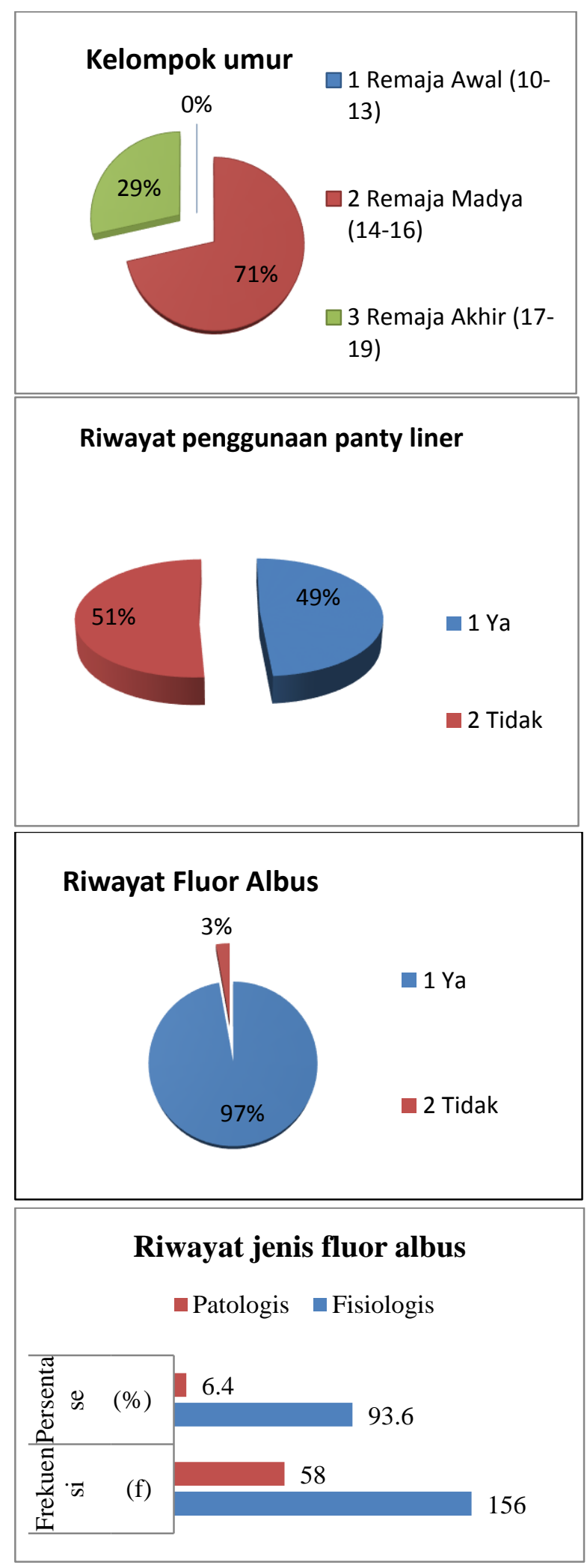




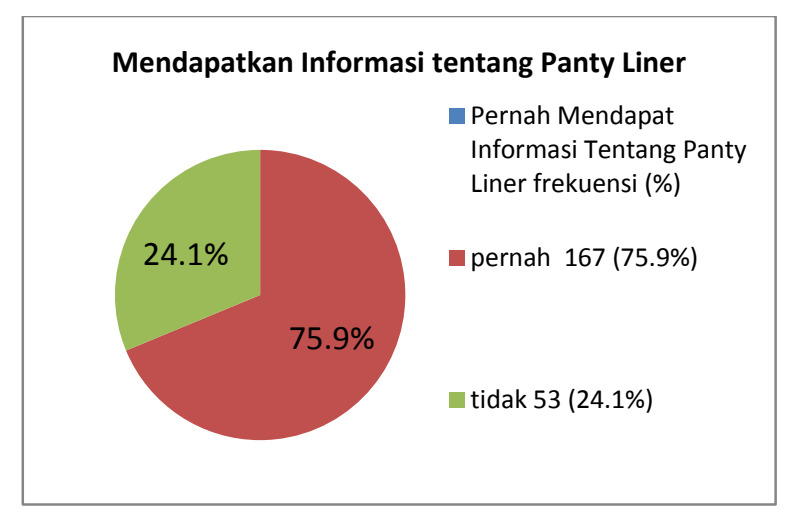

\section{Remaja menggunakan} Panty liner

Total

\begin{tabular}{lcccccc}
\hline \multicolumn{7}{c}{ Kejadian Fluor Albus } \\
\hline Pernah & $\%$ & Tidak & $\%$ & Total & $\%$ & P value \\
& 106 & 98,15 & 2 & 1,85 & 108 & 0,434 \\
Pernah & & & & & & \\
Tidak & 108 & 96,43 & 4 & 3,57 & 112 & \\
& & & & & & 220 \\
\end{tabular}

Menurut hasil yang diperoleh dari penelitian ini dinyatakan bahwa dari 108 Remaja yang menggunakan Panty liner didapatkan $106 \quad(98,15 \%) \quad$ Remaja mengalami Fluor Albus, dan berdasarkan statistik tidak terdapat hubungan yang signifikan antara Penggunaan Panty Liner dengan kejadian Fluor Albus, yang dibuktikan dengan nilai $\mathrm{P}$ - value $>0,05$ yaitu $\mathrm{p}=0,434$.

Hasil penelitian diatas berbanding terbalik dengan teori Farage (2007), panty liner meningkatkan populasi Eubacterium species di vagina dan menurunkan jumlah Lactobacillus species di vagina sebagai flora normal sehingga akan memacu pertumbuhan organisme penyebab keputihan. Pemakaian panty liner juga dapat mentransfer flora intestinal seperti Eschericia coli ke dalam vagina dan pemakaian panty liner non breathable dapat meningkatkan risiko kandidiasis.

Penelitian yang dilakukan Persia Anissa (2013) juga berbanding terbalik dengan hasil penelitian yang telah dilakukan peneliti, bahwa terdapat hubungan yang bermakna antara pemakaian panty liner dengan kejadian fluor albus pada siswi SMA di Kota Padang dengan uji statistik yang diperoleh, nilai $\mathrm{p}=0,000$.

Hal tersebut terjadi karena responden menggunakan panty liner dengan baik sehingga tidak adanya peningkatan jumlah bakteri yang disebabkan karena kelembaban daerah kewanitaan. Daerah kewanitaan lebih terjaga kebersihannya karena kering sehingga tidak meningkatkan pertumbuhan jamur atau bakteri. Hasil ini sesuai dengan pernyataan (Ika, 2011 dan Salika, 2010) yang menyebutkan bahwa tidak dianjurkan untuk terlalu sering menggunakan pantyliner, gunakanlah pantyliner sesuai dengan kebutuhan, artinya ketika mengalami keputihan yang banyak sekali, dan gunakanlah pantyliner yang tidak berparfum untuk mencegah iritasi, dan 
sering mengganti pantyliner saat keputihan.

Hal ini juga sesuai dengan teori (Wijayanti, 2009) yang menyatakan perilaku keputihan sejak dini perlu di tingkatkan oleh para remaja. Misalnya dimulai dari kesadaran untuk menjaga kebersihan di sekitar organ intim, menjaga personal hygiene dan gunakan panty liner di saat perlu saja. Dan sesuai dengan teori (Saydom, 2012), penggunaan panty liner seharusnya dipakai pada saat mengalami keputihan yang tidak nyaman dan berlebihan.

Hasil ini juga sesuai dengan penelitian Persia Anissa (2013) yang memperoleh hasil responden yang menggunakan panty liner dengan relatif sering tidak mengalami kejadian keputihan yaitu orang $(8,3 \%)$. Tidak adanya kejadian keputihan pada responden yang menggunakan panty liner dengan relative sering disebabkan karena cara penggunaannya yang tepat yaitu selalu mengganti panty liner kurang dari 5 jam sekali dalam sehari sehingga daerah kewanitaan selalu kering dan tidak terjadi pertumbuhan jamur atau bakteri penyebab keputihan.

\section{KESIMPULAN DAN SARAN}

Berdasarkan hasil penelitian yang telah dilakukan peneliti di SMK Muhammadiyah 2 Pekanbaru pada tanggal 27 Februari 2017 dengan cara menyebarkan kuisioner yang berisikan pernyataan tentang panty liner dan fluor albus dinyatakan bahwa dari 108 Remaja yang menggunakan Panty liner didapatkan 106 (98,15\%) Remaja mengalami Fluor Albus, hasil uji chi square menunjukkan tidak ada hubungan yang signifikan antara penggunaan panty liner dengan kejadian fluor albus di SMK Muhammadiyah 2 Pekanbaru, dengan nilai P-value 0,434

Berdasarkan hasil penelitian tersebut terdapat beberapa saran yang dapat di sampaikan kepada Remaja Putri,antara lain:

1. Diharapkan pada remaja putri agar lebih berhati-hati jika memilih dan menggunakan produk

2. Gunakan panty liner dengan lapisan berpori, mempunyai daya serap yang tinggi, dan mempunyai permukaan yang lembut

3. Jangan gunakan panty liner setiap hari

4. Gunakan panty liner hanya jika cairan yang keluar dari vagina terasa banyak

5. Jika menggunakan panty liner gantilah setiap 4-6 jam sekali

6. Setelah buang air kecil diharapkan agar mengganti panty liner yang digunakan

7. Gantilah panty liner jika keeadaan terasa lembab

\section{DAFTAR PUSTAKA}

Arismaya, Anggun Mita. (2015).

"Hubungan Perawatan Genitalia

Dengan Kejadian Pada Santriwati

Pondok Pesantren Al- Iman

Sunowono Kabupaten Semarang”.

Karya Tulis Ilmiah. Akademi kebidanan Ngudi Waluyo Umran

Astuti, widya (2016) Hubungan penggunaan panty liner dengan

kejadian keputihan di SMA Muhammadiyah 3 Yogyakarta. Skripsi Universitas 'Aisiyah Yogyakarta

Azizah, Nur. 2015. "Karakteristik Remaja Putri Dengan Kejadian Keputihan Di SMK Muhammadiyah Kudus". JIKK VOL. 6 NO. 1 JANUARI 2015 57-78

Benita, rena, nydia. 2012. "Pengaruh Penyuluhan terhadap Tingkat 
Pengetahuan Kesehatan Reproduksi pada remaja Siswa SMP Kristen Gergaji. Karya Tulis Ilmiah. S1 Sarjana Kedokteran Universitas Diponegoro

Darmasih, Ririn. 2009. "Faktor Yang Mempengaruhi Perilaku Seks Pranikah Pada Remaja SMA Di Surakarta”. Skripsi. S1 Kesehatan Masyarakat. Ilmu Kesehatan Universitas Muhammadiyah Surakarta

Dwi, Febriaristika. 2015. "Pengaruh Penggunaan Pantyliner Terhadap Kejadian Keputihan Pada Siswi SMK di Malang”. Skripsi. S1 Keperawatan Universitas Muhammadiyah Malang

Efendi, Ferry,, dan Makhfudli. 2009. Keperawatan Kesehatan Komunitas. Jakarta: Salemba Medika

Hartati, Sri (2012). Hubungan Tingkat Pengetahuan Tentang Kesehatan Reproduksi Wanita Dengan Perilaku Pencegahan Keputihan Pada Siswi Di Sma Negeri 1 Jatinom, Skripsi S1 Keperawatan Universitas Muhammadiyah Surakarta

Kementrian Kesehatan Republik Indonesia. "Pembalut yang Beredar Sesuai Syarat Kesehatan”. Rabu, 08 Juli 2015 di www.depkes.go.id

Kusumastuti Ambar. 2014. " Peran Komunitas dalam Interaksi sosial Remaja di komunitas Angklung Yogyakarta”. Skripsi. S1 Pendidikan Luar Sekolah Universitas Negeri Yogyakarta

Mahmudah, Yaunin yaslinda dan Lestari yuniar (2015). "Faktor-faktor yang berhubungan dengan Perilaku Seksual Remaja di Kota Pada Padang. Artikel Penelitia Pendidikan
Dokter Fakultas Kedokteran

Universitas Andalas. Padang.

Novia, Vivi. 2013. "Gambar Pengetahuan Remaja Putri Tentang Keputihan Fisiologis". Penelitian DIII Kebidanan Universitas Muhammadiyah Ponorogo

Nurlita, Widya. (2014). Gambaran tingkat pengetahuan dengan perilaku menjaga kebersihan organ genetalia eksterna pada siswi MI pembangunan. Universitas Islam Negeri syarif Hidayatullah: Jakarta

Nurmalasari Lia (2015) Hubungan Antara Tingkat Pengetahuan Remaja Putri Mengenai Kebersihan Genitalia Eksterna Dan Kejadian Keputihan Di Sma Negeri 1 Sukodono. Skripsi Fakultas Kedokteran Universitas Muhammadiyah Surakarta

Persia annisa, Rina, dan Elizabeth. (2013). "Hubungan Pemakaian Panty Liner Dengan Kejadian Fluor Albus Pada Siswi SMA di kota Padang Berdasarkan Wawancara Terpimpin (Kuesioner)". Artikel Penelitia Pendidikan Dokter Fakultas Kedokteran Universitas Andalas. Padang.

Purnamasari, Rita (2012) Hubungan Pengetahuan Dan Prilaku Remaja Putri Dengan Kejadian Keputihan Di Kelas XII SMA Negeri I Seunuddon Kabupaten Aceh Utara. Jurnal Kesehatan Masyarakat.STIKes U'Budiyah Banda Aceh.

SindoNews.com . "YLKI Anjurjan Wanita Pakai Pembalut Kain”. Rabu, 08 Juli 2015

dihttp://lifestyle.sindonews.com/read /1021602/155/ylki-anjurkan-wanitapakai-pembalut-kain-1436346202

Wahyuni Sri. (2013). Tingkat Pengetahuan Siswi Kelas Xi Tentang Personal 
Hygiene Dalam Mencegah Wahyuni Sri. 2013. "Hubungan Keputihan Di SMAMuhammadiyah penggunaan Panty Liner dengan 1 Sragen. KTI. Program Studi kejadian Dermatitis Kontak Iritan". Diploma III Kebidanan Sekolah Tinggi Ilmu Kesehatan Kusuma Thesis. Universitas Muhammadiyah Jakarta.

Husada Surakarta 